\title{
Studying in 3D Environments
}

\author{
http://dx.doi.org/10.3991/ijoe.v10i3.3340 \\ R. Marcelino, J.B. Silva, V. Gruber, S.M. Bilessimo, J. Oliveira, S. B. Santana, I. Mello \\ Federal University of Santa Catarina, Araranguá(Brasil)
}

\begin{abstract}
The present article show a new frontier of knowledge faced with the use of new information and communication technologies applied to students the initial series. The following article is the result the use of a $3 \mathrm{D}$ environment - Virtual World - developed by the Laboratory for Remote Experimentation (RexLab) for students and teachers in the first years of elementary school in Classes Connected Project, conducted in partnership with the University of the State of Santa Catarina (UDESC) and Federal University of Santa Catarina (UFSC). Through significant experiences and the use of educational technologies in 3D virtual environments, we sought to provide this 3D space the possibility of multiple choice, mobility, virtualization of everyday life, interaction and modeling environments releasing students and teachers of spaces and rigid times and the massive use of processes of knowledge transmission. The technologies that at first were used separately, are in a plural and challenging environment.
\end{abstract}

Index Terms-3D Virtual World, children, education, educational environments.

\section{INTRODUCTION}

We are in a moment of change, of adaptation to emerging technological cultural reality in which the rate of change in science and technology prints in all areas, especially education, new learning paradigms and interaction in the educational process. New technologies are becoming, increasingly, important tools of our culture. Their use is a concrete means of inclusion and interaction in the world [1]. Communication technologies extended to education are changing the school environment and creating new methods of learning. The classical concept of the classroom is deprecated. - The 3D virtual worlds are increasingly regarded as a computational extension of the real world, with people, places and objects with whom to can interact. Their resources (avatars) enable users to feel increasingly integral part of the world, narrowed the distance between the real and virtual [2]. Using OpenSim virtual world, was aimed at bringing it real everyday improving and complementing educational methodologies and techniques known in the real world. Using current platforms that enable the offering of educational content that can present many different shapes and use different media, such as video, audio, animation and simulation, conferencing chat among others. In the long term, the spread of 3D virtual worlds based navigation and mobility will facilitate the transition to this type of approach to teaching and learning [3]. In Virtual World, the educational practice can function similarly to real world way, with teacher, student, classroom, presentation slides, desks of student, teacher's desk and even the use of simple rules of behavior [2]. The resources offered by virtual platforms make the most efficient classes. Of conveying information, the teacher becomes a guide. The student in turn, assumes the role of responsibility for learning instead of being merely passive observer information [1]. New technologies can support and provide learning scenarios (Figure 01) in cooperative / collaborative group where the student is the author.

With the use of new technologies, a personalized environment for elementary school children was created. Through the platform multiplayer, students accessed the 3D Virtual World from their schools. Explore the environment and studied the contents of the curriculum matters, such as Arts and Sciences in their classrooms. The Virtual World has been accessed by more than 500 students from four different elementary school in the state of Santa Catarina. The museums and interactive rooms created in 3D Virtual World were used as a pedagogical support for content studied in class later. Through this immersion, students from different schools, with different geographical locations, have met in the same environment, which favored the exchange of experiences, learning and socializing.

\section{THE REXLAB}

Remote experimentation is an area of research that aims to expand human capacity beyond its limits, using the resources of the Internet and other technological means capable of providing remote access, enabling the sharing of resources in general. In other words, it is possible to operate a remote device, or a remote location of the same.

From this concept emerged in 1997 the Laboratory for Remote Experimentation (RexLab), the Federal University of Santa Catarina (UFSC), which currently counts on a network of 12 universities (Rexnet) in 5 different countries. One of his goals is to meet the need of social appropriation of science and technology, popularizing scientific and technological knowledge. Encourage young people to take their place in the technological and scientific careers pursue initiatives that integrate science education to the educational process by promoting the improvement due to upgrade / modernize education at all levels, emphasize actions and activities that enhance and encourage creativity, experimentation and interdisciplinary.

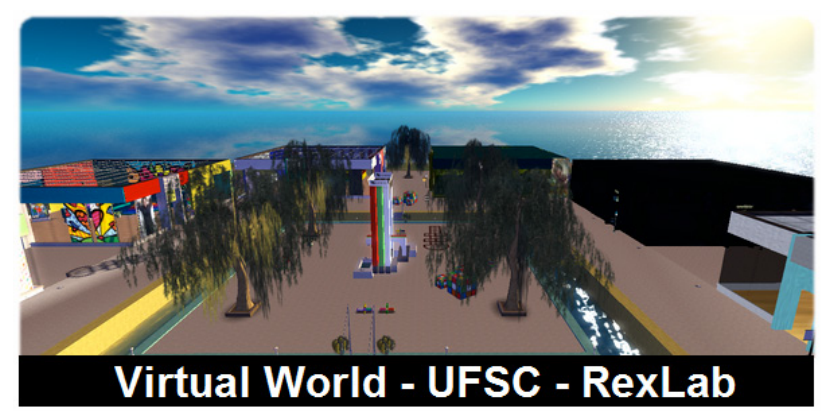

Figure 1. Virtual World 3D Developed by RexLab 
The RexLab has as main research projects Remote Experiments in physics that enable access to resources that people would not have. Enable engineers, technicians in general, scientists and students to make use of large equipment, expensive and perhaps dangerous handling, from their offices and / or their homes. Thus, therefore, reduces travel costs, saves time and allows access for a greater number of people. The teaching-learning Resources Project integrating 3D Virtual World and Remote Experimentation contemplating the implementation environment, proposes the use of $3 \mathrm{D}$ social representations, with the goal of providing access to information dynamically and interactively in a virtual environment closer to the physical reality students, thus facilitate, and enhance student motivation in virtual learning tasks.

\section{D VIRTUAL WORDS}

The 3D Virtual World is a cyberspace. Cyberspace is an excellence environment, which the actions can be logged and transformed into exploitable data [4]. In these places, the students have the freedom to seek new forms of abstraction immersed in a process of discovery, exploration and change the current reality content, beyond the endless construction of knowledge.

The computer is at the same time, reading machine and typewriter, planetarium and museum worldwide virtual library of all images and screen-painting machine, tool universal music and echo or metamorphosis of all camera sounds [5].

The immersion of students and teachers in this context facilitates the acquisition of knowledge and skills, where they can interact with their own reality. At the same time, educators have prejudices, norms and values that come into play when using learning technologies that have an impact on their interpretation and translation of these technologies into practice [6]. The interaction and the results from our experiments and real instruments infer valid scientific conclusions regarding the observed phenomena. This approach allows students to actively participate in the search for knowledge, a constructivist perspective [7].

$3 \mathrm{D}$ virtual worlds provide experience sensory experiences which in turn are not experienced in traditional learning environments [...] even if Second Life is something totally on-the-computer, it clearly activates pathways in our brain we use to deal with the physical space and beings "[8]. In 3D Virtual World, there is a sense of localization that justifies the idea of immersion.

The Virtual World 3D allows:

- To create opportunities immersion of students in the virtual environment provided by creating the feeling of being inside the environment;

- Facilitate interaction with objects in the virtual environment, such as moving objects and opening doors or navigating the virtual environment in the direction desired.

- Motivating students and teachers so that there is interaction, and that way stimulus active participation.

- Promote to conduct experiments in three dimensions by creating new objects and places within the virtual world;

- Develop activities that can be applied differently depending on the rhythm of each;
- Ensure that the restriction of further experience at the end of regular class time does not exist;

- Provide a collaborative environment where the student is primarily responsible for the acquisition of new knowledge;

- Allow exchange of experiences and knowledge online;

- Create a space where students can express their individuality through the construction of avatars.

The Virtual World 3D was developed to allow new forms of abstraction of knowledge through the use of technology in the classroom. Given the ease of use of technology by children, Virtual 3D World was a remote experiment wide acceptance.

\section{OPENSIM}

The OpenSim is a free software based on the Second Life version and is formed by a set of technologies that, when combined, provide an interface to a threedimensional computer generated world, so that the user has the feeling of actually being in this world and starts to interact intuitively with this immersive and dynamic environment. This three-dimensional immersive virtual environment (metaverse) simulates the social lives of users in a surreal virtual environment generated from the $3 \mathrm{D}$ vector graphics combined with textures. In "generated world" its residents interact in the graphical environment through their avatars [2]. The OpenSimulator project (Figure 02) is a Server Virtual Worlds derivative called VirtualWords Server with BSD license that can be used to create and develop 3D Virtual Environments.

Second Life offers great educational opportunities and served as a model to develop a virtual environment and educational purposes. This manner the Opensim to be free and have the same characteristics has become a tool used to virtually recreate real environments. Being developed by several developers and ready for use, OpenSimulator can be used to create similar to Second Life (tm) environment be able to run in standalone or connected to other OpenSimulator instances through the "grid" technology embedded mode. It is possible to expect in OpenSim to obtain 90 percent of the functionality of Second Life ". This is a project with modular architecture that can be easily extended to produce interactive 3D applications more specialized. Due to their modular nature and clean is possible for users to extend functionality through plug-in modules to suit your application. OpenSimulator currently has obtained financial support from large companies like Nokia, IBM, Intel and Microsoft [9]. A virtual environment such as Open Simulator can provide structure to strengthen educational practices and communicative processes that solidify dialogue and cooperation group for pedagogical use and contribute to the group learning and the process of intellectual [2] collaboration. The group learning aims to stimulate the capacity for dialogue, "for the Greeks, dialogue denoted the free flow of meaning in the group, allowing new ideas and perceptions those individuals would be unable to be alone" [10] as shown in Figure 2 with information on OpenSim. 


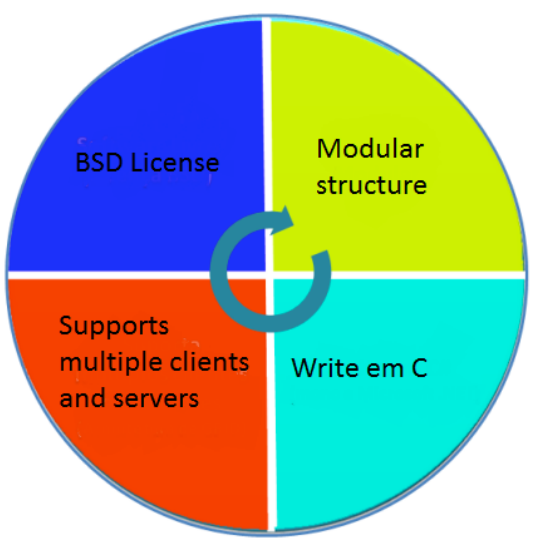

Figure 2. Virtual World 3D Developed by RexLab

\section{PracticAl APPLICATION}

\section{A. Developed environments}

\section{1) MUSEUM OF MODERN ART}

The Brazilian Museum of Modern Art is an environment designed to stimulate visual and through hearing the visitors. Bring inside an exhibition of works by Brazilian artist Romero Brito modern. In Figure 03 we can see the museum which contains several frames produced by the author, with name and date of his creation. Also includes features video (Youtube link) which tells of the author's biography.

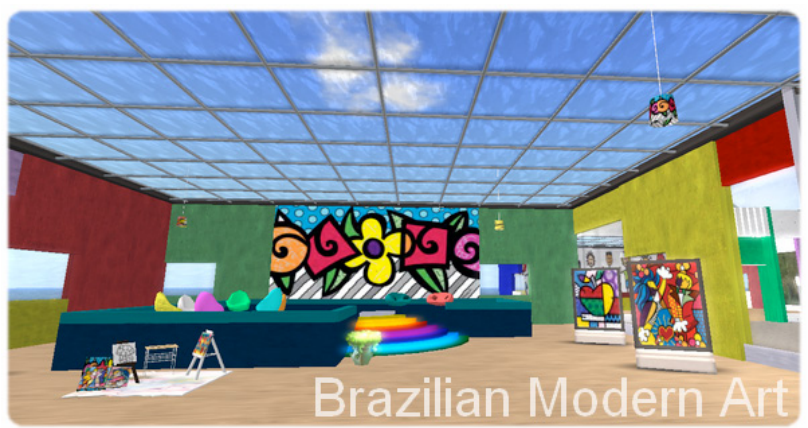

Figure 3. Museum of Modern Art in 3D virtual world. Developed by RexLab

\section{2) PLANETARY}

The planetarium is an environment designed for the study of the solar system. In Figure 04 display each planet constructed like a replica of the real environment (texture). Visitors can fly through space creating the feeling of being there, interacting and getting to know the characteristics of each planet.

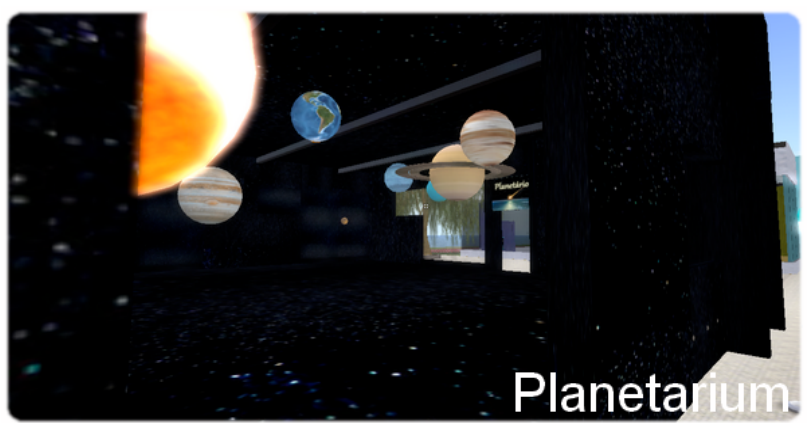

Figure 4. Planetarium 3D virtual world. Developed by RexLab

\section{3) THE MUSEUM OF NATURAL SCIENCES}

The museum of natural sciences in Figure 05 is composed of a primitive environment with plants and sounds. When walking through the space the visitors are inserted into a sensory environment where they can learn more about these endangered animals. Here the use of sound sources has as its main objectives the simulation of reality, creating the illusion and reconstitution of the environment.

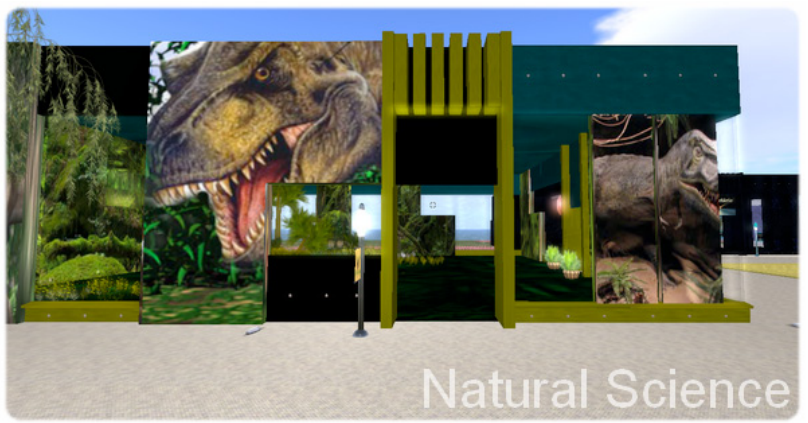

Figure 5. Museum of Natural Science in the 3D virtual world. Developed by RexLab

\section{4) INTERACTIVE LOUNGE}

In this place (Figure 06) visitors are invited to leave their passage recorded by the virtual world, this record is done by uploading productions made outside the virtual world and placed on display in this room murals. The resources used can be images, videos, texts and others.

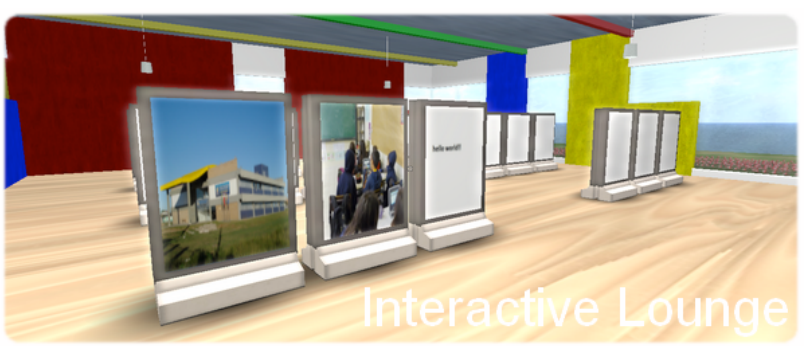

Figure 6. Interactive Lounge in 3D virtual world. Developed by RexLab

\section{5) INTERACTIVE ROOM}

This room (Figure 07) was constructed based on a real educational environment containing desks arranged to promote interaction of all visitors. Contains audiovisual resources, projection screens, PowerPoint presentations, video conferences and everything connected to the Internet.

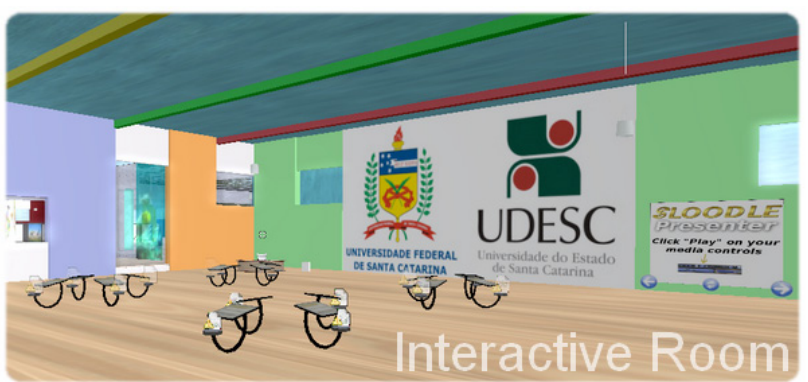

Figure 7. Interactive Room in 3D virtual world. Developed by RexLab

The Virtual World 3D - RexLab / UDESC (Figure 08) created over the OpenSim platform - with the potential to promote ludic, interactive and immersive educational ex- 
periences. An environment where students and teachers to test, explore and interact through a virtual learning environment that allows communication and online collaboration.

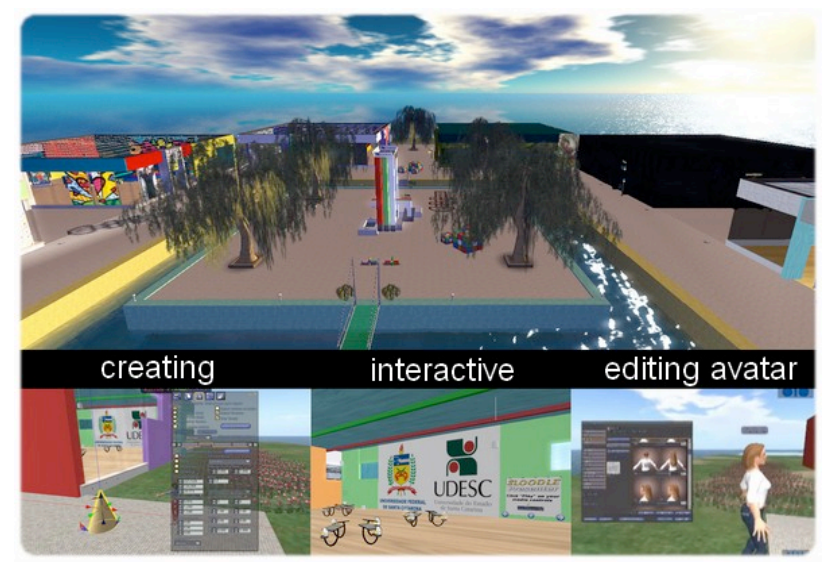

Figure 8. Virtual World 3D Developed by RexLab

The involvement of students in activities in the Virtual World demonstrated a high pedagogical potential, allowing interaction with people and objects in simulated environments, in a controlled manner, as well as the development of learning processes with a playful component. In Virtual World has been possible to develop activities that would be impossible or just enforceable in a real environment, such as flying through space or walking by prehistoric forests. The first contact with the Virtual World RexLab / UDESC performed by students and teachers involved in this project was promising the level and domain knowledge of educational technology was beyond the expectations of the team, reaching higher levels in satisfactory standard. $75 \%$ of students $75 \%$ and $45 \%$ of teachers were able to accomplish the simulation of real experiences, interaction with three-dimensional environments, the possibility of creating objects, virtual museums, upload images created outside the virtual world among others.

\section{DATA COLLECTION - RESEARCH FiRST CONTACT WITH A NEW TECHNOLOGY}

Currently the presence of information and communication technologies in everyday life is growing fast and influencing school life. Therefore one can not deny the relationship between knowledge in the field of computer science and other fields of learning. This is a new form of language and communication, a new code: digital language. Other relevant forms of communication throughout human history still shows great resistance on the part of humans. Educational technologies and their use has provided countless discussions about the positive and negative issues. The technical-scientific development is propelling new discoveries and generates large changes in the school routine. The requirement of a growing domain of knowledge and skills to handle this diverse and complex reality, impose new conceptions of education, school and education.

The development of techniques of science and technology must be understood in close collaboration with the social, political, economic and cultural determinations. These activities build a relationship of man with nature, is the human effort to create tools that overcome the difficul- ties of natural barriers. In presenting this new tool for teachers and students of public schoolswe harvested measurable data showing two distinct realities marked by two generations with different technological concepts.

The first contact with the Virtual World of teachers and students as shown in Table 1 and Table 2 was recorded through a questionnaire which collected data are arranged below our search and infer important information about the use of technology in everyday school life.

TABLE I

STUDENTS - LEVEL OF KNOWLEDGE



What is your domain and knowledge
about educational technologies?

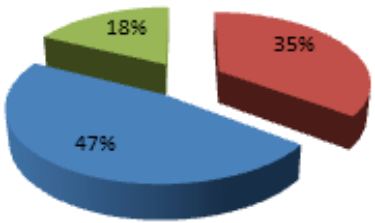

- Little

- Average

Advanced

Using technology aims to increase the efficiency of human activity in all spheres of performance, especially in the educational. For a society with such deep features of inequality, public school becomes the only source of access for children of the working class to the information and technological resources.

The current model of knowledge transmission points to an education that develops on a "planetary", breaking down the barriers of the teaching learning process. The school as a social institution is convened to attend satisfactorily the requirements of modernity. We are witnessing these technology innovations, and is of fundamental importance that the school learn the knowledge related to them so you can transfer them to your students, it is necessary that the school propitiates such knowledge and skills necessary for the student to exercise it fully their citizenship. Contact with new technologies left impressions on first contact as shown in Table 3 and 4, which shows the data obtained among students and teachers. 
TABLE III

STUDENTS - FIRST IMPRESSION

\section{What was your first impression when you logged in Virtual World?}

096

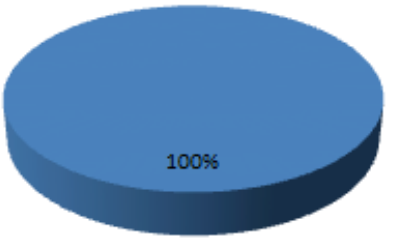

TABLE IV

TEACHERS - FIRST IMPRESSION

\section{What was your first impression when you logged in Virtual World?}

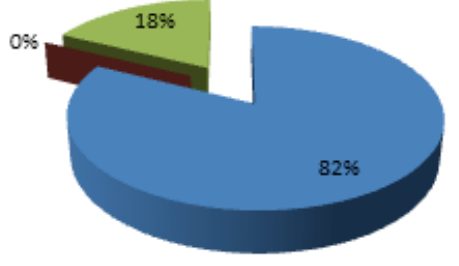

- Good

- Bad

- Unanswered

Front this new situation, educational institutions face the challenge of not only incorporate new technologies in the teaching process, but also to recognize and from the ideas and experience that students and teachers have about these technologies to design, develop and evaluate educational practices promoting the development of a reflective stance on the use of technology in the classroom. What can be shown in Tables 5 and 6 , where students and teachers demonstrate the difficulty level of this first contact with a new technology.

The purpose of this research from the collective and collaborative work is experiencing some resources to create a virtual learning environment that allows the organization of educational work in the educational environment, and also allows the teacher to use these resources for the organization of their pedagogical practice. To develop a practice in the school integration of technologies in the organization of educational work, from the reflections made, is necessary define the virtual learning environment. As the Tables 7 and 8 3D Virtual World is considered a learning environment space that aims to educational action.

To develop a learning environment, we try to pay attention to several characteristics that make this place suitable to the teaching-learning so as to provide all forms of student-computer interaction as shown in Table 9, 10 and 11. Projected to ensure the success of all proposed educational objectives, oriented for use in specific teaching situations and to elicit interest in students and creating greater motivation in the classroom.
TABLE V

STUDENTS - DIFFICULTY LEVEL

\section{Did you have any difficulties?}

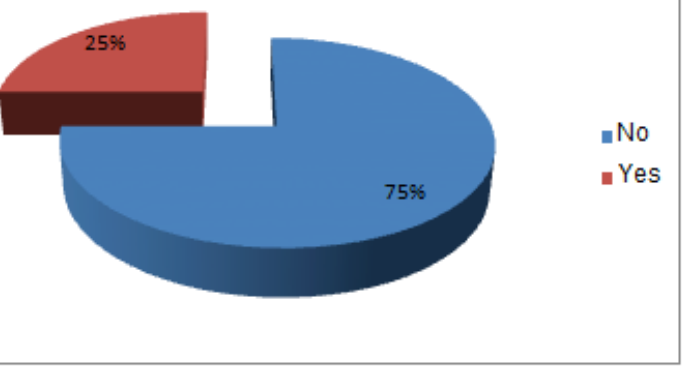

TABLE VI

TEACHERS - DIFFICULTY LEVEL

\section{Did you have any difficulties?}

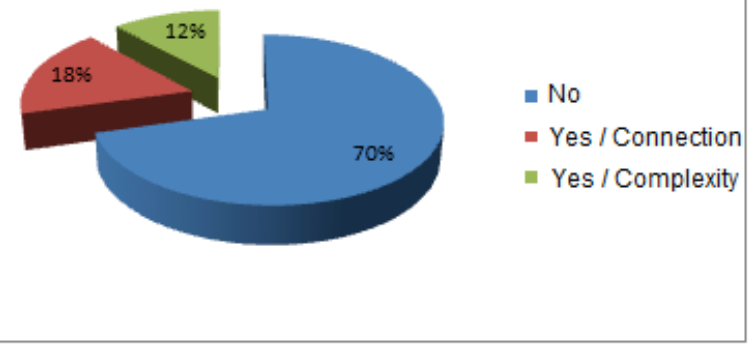

TABLE VII

STUDENTS - EDUCATIONAL CONTEXT

\section{Has the virtual world applicability in a pedagogical context?}

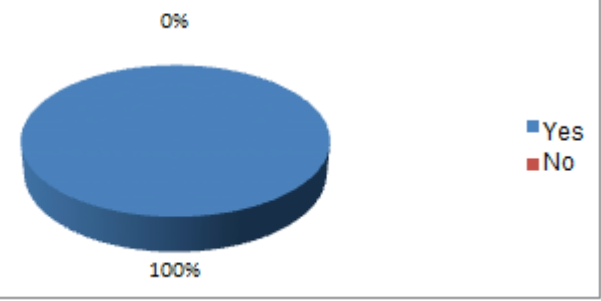

TABLE VIII

TEACHERS - EDUCATIONAL CONTEXT

\section{Has the virtual world applicability in a pedagogical context?}

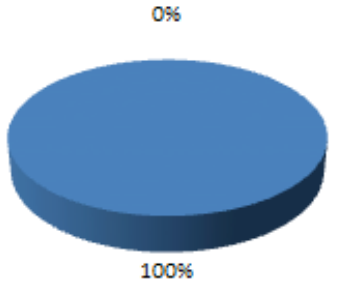

"Yes $\because$ No 
TABLE IX

STUDENTS - POSITIVE ASPECTS

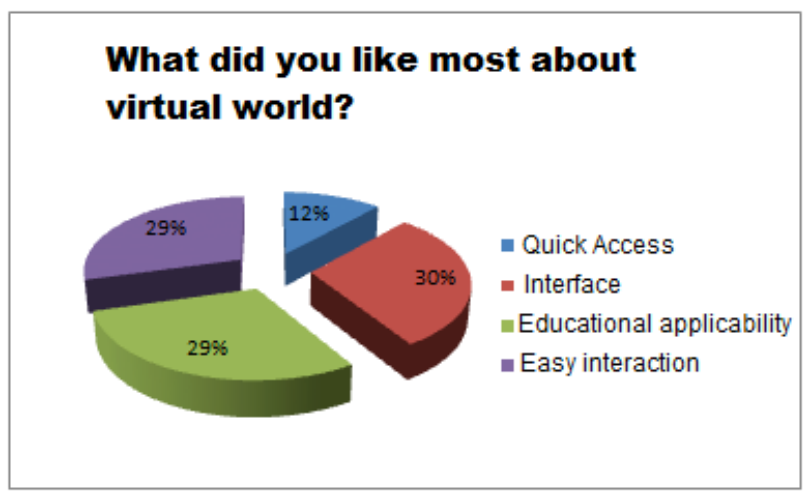

TABLE $X$

TEACHERS - POSITIVE ASPECTS

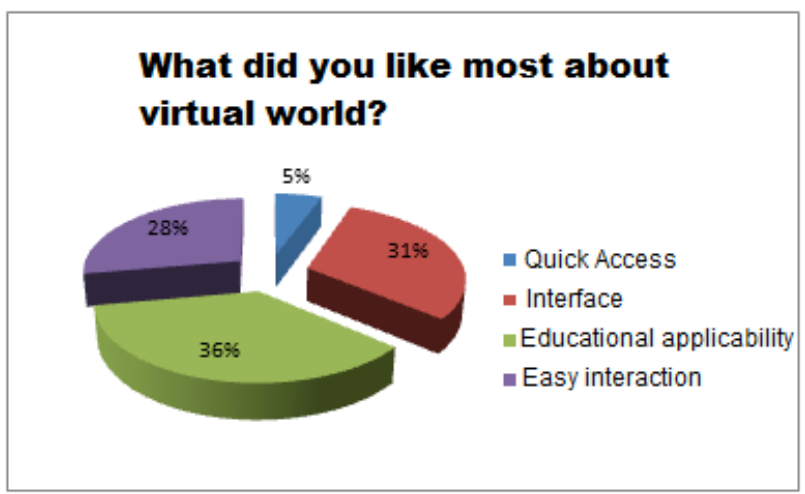

TABLE XI

NEGATIVE ASPECTS

\section{What you did not like in the virtual world?}

$0 \% 6$

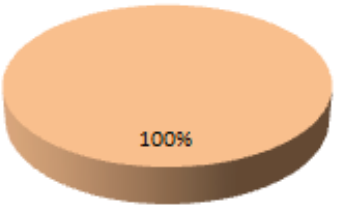

- Quick Access

- Interface

Educational applicability

- Easy interaction

w Other / Language

The Virtual World 3D promote the democratization of online technology and resources available remotely. Considering that the network resources are highly interactive, dialogic and intertextual provides a collaborative production fulfilling its function of virtual learning environment as shown in Tables 12 and 13.

Therefore the 3D Virtual World is the possibility of significant change in the teaching and learning process and, in parallel, rest assured that the public school is complying its real function.

TABLE XII

COMPARATIVE
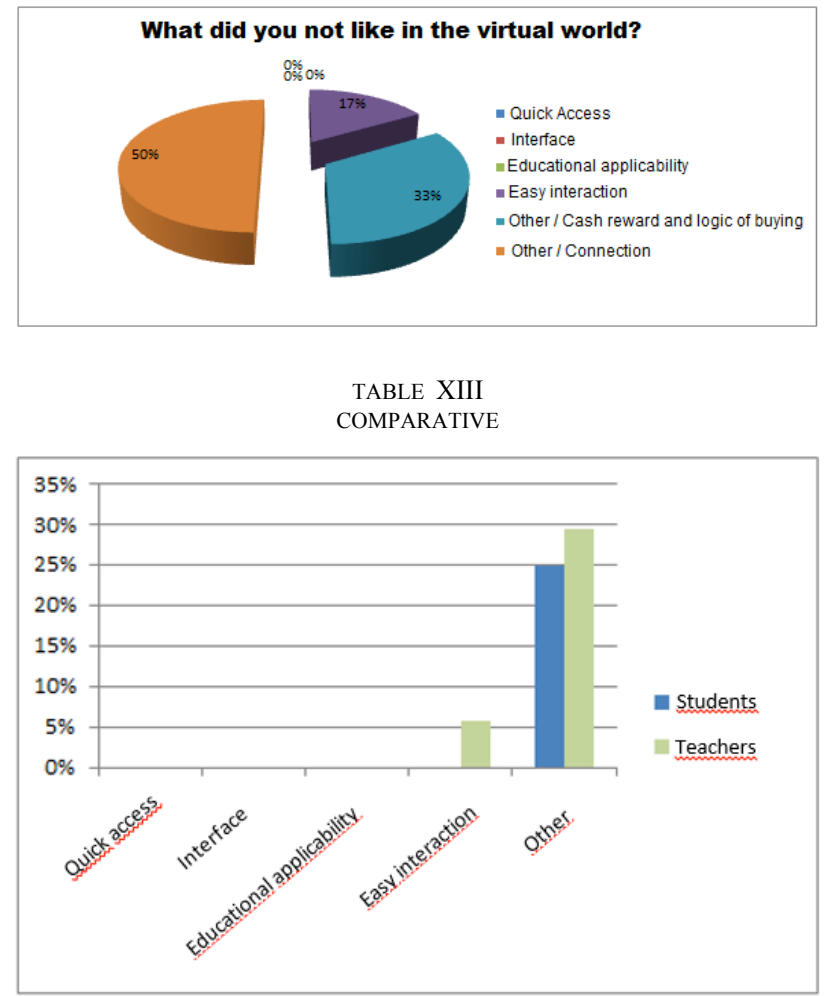

VII. CONCLUSION

The virtual world can not be handled as just "another tool" to enhance learning. Should be considered as a powerful tool for learning distinct from traditional methods. Traditional methods differ from the exact 3D Virtual Worlds for not allowing the discovery and exploitation of knowledge, which prevents students construct their own knowledge more lastingly because they are not grounded in personal experience. This project brought to new participants glances on the use of technology in the classroom, reports of teachers and students have signed the need to invest in similar environments to fill the gaps in today's classroom and make this new world of technology this also in an educational context. Many were the contributions of teachers and students who left their explicit expectations for future access. Many would like an environment in his mother tongue, the possibility of building new places for themselves. Theme Rooms to reproduce educational situations as the Big Bang, History, Natural History Museum of Fossils and different ambiences of our reality. Also can create the center of the earth, underwater world, solar system planets, elements that could be used by persons special needs places where they could interact through music with other connected users and also for thematic disciplines regular education rooms. 


\section{REFERENCES}

[1] M. L. da Silva Toquato Costa, Ambientes virtuais de aprendizagem na educação à distância na pós-modernidade. Available: $<$ http://dialogica.ufam.edu.br/PDF/no2/ambientesvirtuais_le lia.pdf $>$. Acesso em: 30 de janeiro 2013.

[2] J. Bento Silva; J. B .M. Alves ; M. Giraldi, A utilização da experimentação remota como suporte à ambientes colaborativos de aprendizagem. In: ICBL - international Conference, 2008. Florianópolis-SC. ICBL - Interactive Computer Aided Blended Learning.

[3] M. Callaghan et al. Circuit Warz, the Games. Collaborative and Competitive Game-based Learning in Virtual Worlds. In: Remote Engineering and Virtual Instrumentation (REV), 2012 9th International Conference on, Derry. 2012.

[4] P. Lévy, O que é virtual? São Paulo: Editora 34, 1997. 160 p.

[5] P. Lévy, A conexão Planetária: O mercado, o ciberespaço, a consciência. São Paulo: Editora 34, 2001. 192 p.

[6] M. Johannesen; O. Erstad; L. Habib, Virtual learning environments as sociomaterial agents in the network of teaching practice. Oslo. Ed. Elsevier Ltd. Volume 59, Issue 2, September 2012, Pages 785-792.

[7] R. Marcelino et al. An extended immersive learning environment for solid mechanics theory and demonstration(s). In: REV2010 The 7th International Conference on Remote Engineering and Virtual Instrumentation. Florianópolis. 2010.

[8] S. Booth, Culture shock in Second Life. Available . Acess in: 22 jan. 2013.

[9] OpenSim, "The Open Simulator Project". Available: $<$ http://opensimulator.org $>$. Acess in: 10/01/2013.

[10] P. Michael Senge, A quinta disciplina: Arte e prática da organização que aprende. 25. ed. São Paulo: Best Seller Ltda., 2001. 532 p.

\section{AUTHORS}

Marcelino R., is a researcher at Universidade Federal de Santa Catarina (UFSC), Araranguá, Brazil. (e-mail: roderval.marcelino@ufsc.br).

Silva J.B., is a researcher at Universidade Federal de Santa Catarina(UFSC), Araranguá, Brazil. (e-mail: juarezbs.silva@gmail.com).

Gruber V., is a researcher at Universidade Federal de Santa Catarina (UFSC), Araranguá, Brazil. (e-mail: vilsongruber@msn.com).

Bilessimo, M.S, is a researcher at Universidade Federal de Santa Catarina (UFSC), Araranguá, Brazil. (e-mail: simone.bilessimo@gmail.com).

Oliveira, J., researcher and academic RexLab Federal University of Santa Catarina (USFC), Santa Catarina, Brazil. (E-mail: janafl30@hotmail.com).

Santana, S.B., researcher and academic RexLab Federal University of Santa Catarina (USFC), Santa Catarina, Brazil. (e-mail: simonebarreto@grad.ufsc.br).

Mello, I., researcher and academic RexLab Federal University of Santa Catarina (USFC), Santa Catarina, Brazil. (E-mail: iurymelo@live.se).

Submitted 23 August 2013. Published as re-submitted by the authors 28 April 2014. 